\title{
IN STENT RESTENOSIS (ISR) IN PATIENTS UNDERGOING PERCUTANEOUS CORONARY INTERVENTION (PCI) FOR CORONARY ARTERY DISEASE (CAD)
}

\author{
Waseem Raja, Naseer Ahmed Samore, Mohsin Saif, Javeria Kamran, Sidra Waheed, Naeem Tariq, Farhan Tuyyab, Abdul \\ Hameed Siddiqui \\ Armed Forces Institute of Cardiology/National Institute of Heart Disease (AFIC/NIHD)/National University of Medical Sciences (NUMS) \\ Rawalpindi Pakistan
}

\begin{abstract}
Objective: To study the frequency of In-Stent Restenosis and its treatment in patients undergoing Percutaneous Coronary Intervention for coronary artery disease.

Study Design: Descriptive cross sectional study.

Place and Duration of Study: Department of Cardiology, Armed Forces Institute of Cardiology \& National Institute of Heart disease (AFIC/NIHD) Rawalpindi, from Jul 2017 to Jul 2019.

Methodology: All the patients who underwent Percutaneous Coronary Intervention for Coronary Artery Disease at our institute were considered for this study. A consecutive sampling method was used and inclusion/exclusion criteria was applied. Following data was obtained; 1) Demographic information and clinical risk factors like history of hypertension, hyperlipidemia, diabetes mellitus, smoking, coronary artery disease characteristics (number of diseased arteries, bifurcation lesions, calcification, chronic total occlusions-CTO and tortuosity) 3), Stent factors (under expansion, fracture, longitudinal miss, stent gap). Data recording, storage, assessment and analysis was done by using SPSS software version 21.

Results: Among 1332 cases, 50 had In-Stent Restenosis with overall prevalence of $3.75 \%$. Mean age of the patients with In-Stent Restenosis was 58.76 ( \pm 9.97), with $45(90 \%)$ male and $5(10 \%)$ female. Diabetes Mellitus was the commonest risk factor $(22.9 \%)$ followed by Hypertension (18\%). Sixty four percent of the patients $(\mathrm{n}=32)$ had Single Vessel Coronary Artery Disease, 14 (28\%) had Double Vessel Coronary Artery Disease and $4(8 \%)$ had Tripple Vessel Coronary Artery Disease. Left Anterior Descending was the commonest coronary artery that developed In-Stent Restenosis, followed by Right Coronary Artery and Left Circumflex respectively. Previously deployed stents which developed In-Stent Restenosis showed longitudinal geographical miss in $16 \%$, stent under expansion in $6 \%$ and stent gap in $4 \%$. There was statistically significant association $(p$-value $=0.02)$ between stent length and frequency of In-Stent Restenosis and it was commonest in stents longer than $30 \mathrm{~mm}$. Eighty six percent $(n=43)$ of In-Stent Restenosis cases in our study group was treated with Drug Eluting Stent followed by Drug Eluting Balloon in 32\% and Plain Old Balloon Angioplasty in 22\%.

Conclusion: History of diabetes mellitus and greater stent length were major risk factors in developing In-Stent Restenosis in our study. DES was the commonest treatment modality used.
\end{abstract}

Keywords: Coronary artery disease, Percutaneous Coronary intervention, Restenosis.

This is an Open Access article distributed under the terms of the Creative Commons Attribution License (http://creativecommons.org/licenses/by/4.0), which permits unrestricted use, distribution, and reproduction in any medium, provided the original work is properly cited.

\section{INTRODUCTION}

Restenosis is the reduction in the diameter of the vessel lumen after angioplasty. Following the introduction of bare-metal stents (BMS) in the mid-1990s for the treatment of coronary artery disease, a new clinical entity emerged called InStent Restenosis (ISR), which is restenosis in an implanted coronary stent ${ }^{1}$. ISR which is currently defined as a $>50 \%$ stenosis of a previously

Correspondence: Dr Waseem Raja, Department of Cardiology, AFIC/NIHD Rawalpindi Pakistan stented segment, occurs in as many as 30\% of all patients receiving bare metal stents (BMS). Despite the advent of the drug-eluting stents (DES) and improved stent design, the rates of ISR in patients treated with DES are as high as $10 \%$. Specifically, the widespread adoption of DES for small arteries, long lesions, complex coronary lesions, diabetes, and a history of bypass surgery has in fact been the trigger for significant numbers of patients re-presenting with DES restenosis in contemporary clinical practice. The treatment of patients with ISR continues to remain a 
challenge, and currently available options include angioplasty alone, repeat stenting with DES or drug-coated balloons (DCB) ${ }^{2}$.

\section{METHODOLOGY}

This descriptive cross sectional study was carried out at the Department of Cardiology, Armed Forces Institute of Cardiology \& National Institute of Heart disease (AFIC/NIHD) Rawalpindi from July 2017 to July 2019. All patients who underwent percutaneous coronary intervention (PCI) for CAD at our institute were considered. A consecutive sampling technique was used. ISR was defined as a reduction in lumen diameter by over $50 \%$ after PCI. CAD was defined as stenosis $\geq 70 \%$ in at least 1 major coronary artery as shown by Coronary Angiography (CA). Following inclusion criteria was applied; Patients older than 18 Years of age, confirmed CAD more than $70 \%$ stenosis as shown by CA and patients who received DES. Unwilling patients, CAD in combination with myocarditis, pericarditis, congenital heart disease, valvular heart disease, and patients with combined immune system disease, infection, tumor, hematologic diseases, or severe liver and renal insufficiency were excluded from the study. A written informed consent was obtained. A detailed history including risk factors was gathered. Demographic characteristics (name, age, gender, residence, and contact number) were recorded for each patient. The following clinical data were collected: (1) baseline data: sex, risk factors of CAD (hypertension, hyperlipidemia, diabetes mellitus (DM), history of smoking, history of alcohol abuse, family history of CAD); (2) conditions of the lesioned vessel and length, diameter, and number of stents; (3) treatment for ISR e.g. POBA, DEB or DES. All the data was entered and analyzed by SPSS-23. Mean and standard deviation was calculated for quantitative variables like age. Chi-square was used for advanced statistics to determine the various association and $p$-value $>0.05$ was considered significant.

\section{RESULTS}

Out of 1332 patients who underwent PCI for CAD, 50 had ISR with overall prevalence of $3.75 \%$. Mean age of the patients with ISR was $58.76 \pm 9.97)$, with $n=45(90 \%)$ male and $n=5$ $(10 \%)$ female. DM was the commonest risk factor $11(22.9 \%)$ followed by Hypertension 9 (18\%).

Sixty four percent $(n=32)$ had SVCAD, 14 (28\%) had DVCAD and $4(8 \%)$ had TVCAD. Left Anterior Descending (LAD) was the commonest coronary artery that developed ISR, followed by right coronary artery (RCA) and left circumflex

Table-I: Baseline caharaceristics and risk factors of study participants.

\begin{tabular}{l|c}
\hline Characteristic & $\mathbf{n ~ ( \% ) ~} \mathbf{n = 5 0}$ \\
\hline Age $($ mean \pm SD) & $(58.76 \pm 9.97)$ \\
\hline Gender & \\
Male & $45(90 \%)$ \\
Female & $5(10 \%)$ \\
\hline DM & $11(22.9 \%)$ \\
\hline HTN & $9(18 \%)$ \\
\hline Family History & $1(2 \%)$ \\
\hline
\end{tabular}

Table-II: Anatomical features and stent factors related to ISR vessels.

\begin{tabular}{|c|c|c|}
\hline & Variables, $n=50$ & n ( $\%)$ \\
\hline \multirow{5}{*}{$\begin{array}{l}\text { Anatomical } \\
\text { Features }\end{array}$} & $\begin{array}{l}\text { Coronary artery vessel } \\
\text { involvement } \\
\text { SVCAD } \\
\text { DVCAD } \\
\text { TVCAD }\end{array}$ & $\begin{array}{c}32(64 \%) \\
14(28 \%) \\
4(8 \%)\end{array}$ \\
\hline & Bifurcation lesion & - \\
\hline & Calcification & $1(2 \%)$ \\
\hline & Chronic total occlusion & $4(8 \%)$ \\
\hline & Tortuosity & - \\
\hline \multirow{4}{*}{$\begin{array}{l}\text { Stent } \\
\text { factors }\end{array}$} & Stent under-expansion & $3(6 \%)$ \\
\hline & Stent Fracture & - \\
\hline & $\begin{array}{l}\text { Longitudinal } \\
\text { geographical miss }\end{array}$ & $8(16 \%)$ \\
\hline & Stent gap & $2(4 \%)$ \\
\hline
\end{tabular}

(LCx) respectively. Previously deployed stents that developed ISR showed longitudinal geographical miss in $8(16 \%)$, stent underexpansion in $3(6 \%)$ and stent gap in $2(4 \%)$. There was statistically significant association $(p$-value $=0.02)$ between stent length and frequency of ISR and it was commonest in stents longer than $30 \mathrm{~mm}$. Eighty six percent $(n=43)$ of ISR cases in our study group was treated with DES followed by DEB in $32 \%$ and POBA in $22 \%$. 
Statistically significant association was found between stent length and ISR using chi-square. ISR was most frequent in LAD 22 (44.1\%) follo- recent report has proposed vascular intimal proliferation and infiltration of local inflammatory cells as the potential underlying mechanism ${ }^{3}$. It is

Table-III: Association between the stent length and in stent restenosis vessels.

\begin{tabular}{l|c|c|c|c|c}
\hline \multirow{2}{*}{ Stent Size } & \multicolumn{4}{|c|}{ ISR Vessels, $\mathbf{n = 5 0}$} & \multirow{2}{*}{$\boldsymbol{p}$-value } \\
\cline { 2 - 5 } & LAD & LCx & RCA & Others & \\
\hline$<20 \mathrm{~mm}$ & $7(46.6 \%)$ & $1(6.6 \%)$ & $3(20.1 \%)$ & $4(26.0 \%)$ & \multirow{2}{*}{0.023} \\
\hline $20-30 \mathrm{~mm}$ & $2(18.1 \%)$ & $4(36.1 \%)$ & $2(18.1 \%)$ & $3(27.1 \%)$ & \\
\hline$>30 \mathrm{~mm}$ & $13(54.1 \%)$ & $1(4.12 \%)$ & $5(20.8 \%)$ & $5(20.8 \%)$ & \\
\hline
\end{tabular}

wed by RCA 10 (20.3\%). Length of the stents (longer than $30 \mathrm{~mm}$ ) was an independent and statistically significant association with ISR.

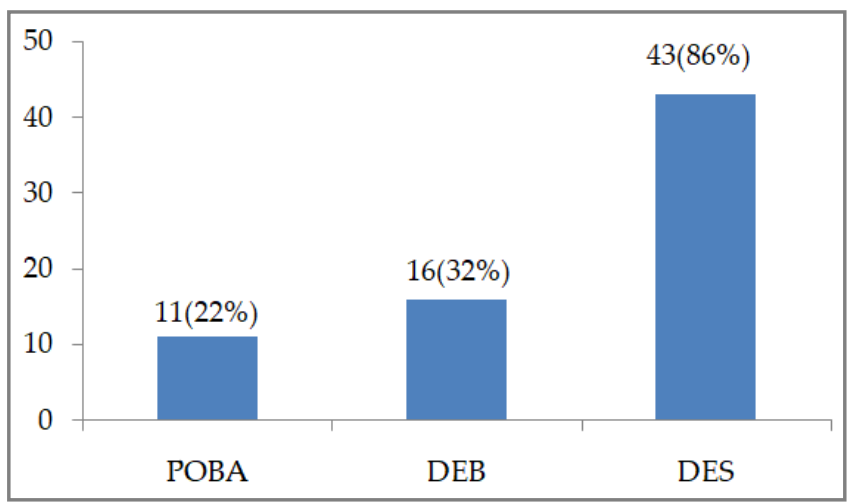

Figure-1: Different treatment options in ISR.

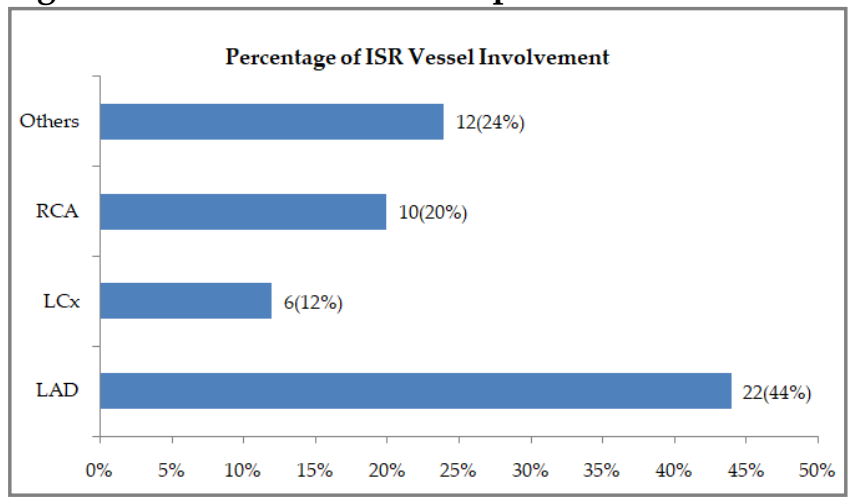

Figure-2: Vessel involvement in ISR.

\section{DISCUSSION}

Coronary stent implantation has significantly improved PCI and enabled the management of early complications of POBA. By preventing elastic recoil and constrictive remodeling, coronary stent implantation decreases the frequency of restenosis after PCI. However, a new complication has accompanied these improvements: in-stent restenosis (ISR). At present, the pathogenesis of ISR after PCI is not fully understood. A postulated that ISR following BMS implantation is predominantly due to neointimal hyperplasia while following DES implantation, the main underlying pathological mechanism is "neoatherosclerosis". Nakazawa, et al, found that neoatherosclerosis as a result of persistent endothelial dysfunction and incomplete neoendothelisation occurs more frequently (31\% vs. $16 \%$ ) and earlier (median: 420 vs. 2160 days) following DES than BMS implantation 4 .

The clinical presentation of ISR is usually recurrence of angina symptoms or occasionally an acute coronary syndrome. In a clinical database, ISR manifested in $52.2 \%$ of cases as Unstable Angina (UA) or Non-ST Elevation Myocardial Infarction (NSTEMI), in $18.5 \%$ as ST Elevation Myocardial Infarction (STEMI) and only in $25.3 \%$ as stable angina ${ }^{5}$. The clinical incidence of ISR after bare-metal stent (BMS) implantation is approximately $20 \%-35 \%$. The use of drug-eluting stents (DES) has led to a decrease in the occurrence of ISR to $5 \%-10 \% 6,7$. In our study the prevalence was $3.75 \%$, which might be lower due to underreporting of clinical significant entity. ISR risk factors can be divided into patient, lesion and procedure related. Our study has shown that DM was the commonest patient related risk factor (22.9\%) followed by Hypertension (18\%). These results seem in line with various studies where $\mathrm{DM}$ has proven to be the strongest predictor for development of both BMS and DES ISR. The long-term hyper-coagulable state, vascular endothelial metabolism, and dysfunction of coronary artery blood flow in diabetic patients can increase the risk of restenosis ${ }^{8}$. Diabetes itself increases the risk of BMS-ISR by $30 \%-50 \% 9,10$. Similarly, the risk of DES-ISR is increased in diabetic patients 
when compared to those without diabetes. Various lesion and procedure related factors have been described in the literature which predispose to the development of ISR. Left Anterior Descending (LAD) was the commonest coronary artery developing ISR in our study group. Previously deployed stents which developed ISR showed longitudinal geographical miss in $16 \%$, stent underexpansion in $6 \%$ and stent gap in $4 \%$. Some of the lesion reltaed factors for ISR are;complex (Type $\mathrm{B}$ and $\mathrm{C}$ lesions), long lesions $>20 \mathrm{~mm}$, artery diamtere $<3 \mathrm{~mm}$, chronic calcific ostial and bifurcating lesions. Stent length is an important determinant for ISR as well; in fact longer stents are an important risk factor for restenosis. A study with median follow-up of 36.9 months observed how patients treated with stent length $\geq 32 \mathrm{~mm}$ had a greater risk of ISR than those treated with a stent $<32 \mathrm{~mm}^{11}$. In our study there was statistically significant association ( $p$-value $=0.02$ ) between stent length and frequency of ISR and it was commonest in stents longer than 30 $\mathrm{mm}$. Finally, also vessel diameter plays an important role as reported by the HORIZONS-AMI study, ISR rate increases significantly when the vascular caliber is $\leq 3 \mathrm{~mm}^{12}$. Peri-procedurals risk factors documented in the literature are; suboptimal apposition, under-expansion of the stent, multiple stents and stent fracture.

Coronary Angiography is used for the diagnosis of ISR, but Intravascular Ultra Sound (IVUS) and Optical Coherence Tomography (OCT) are additional diagnostic modalities. IVUS allows for a detailed display of the stented segment during an assessment of the cross-section of individual vessel wall layers. It is able to exclude possible mechanical causes of ISR (under-expansion, stent fracture, etc.) and provide detailed information on the extent of neointimal hyperplasia $^{13}$. OCT uses beam deflection with a frequency near to infrared light. This way, it achieves a significantly higher resolution compared to IVUS and allows for a more detailed assessment of stented segment.

Current treatment for ISR (whether BMS or DES) is based on DES or DCB. Repeated POBA or BMS implantation was associated with a high (nearly $40 \%$ ) recurrent ISR ${ }^{14}$, cutting balloon dilatation did not reveal any significant benefit 15 , and rotational atherectomy even led to outcomes inferior to POBA ${ }^{15}$. This treatment was established in the SISR and TAXUS V ISR trials, which compared the implantation of DES to relatively complicated brachy therapy. Brachy therapy was one of the most promising treatment options for patients with neointimal hyperplasia related to BMS-ISR. Randomized clinical trials in patients with ISR showed it to be more effective in preventing ISR progression and improving clinical outcomes than either POBA or de-bulking procedures with laser or atherectomy ${ }^{16}$. However, the advent of DES signaled the end of brachy therapy. The 2 large randomized clinical trials which compared the efficacy of brachy therapy versus DES in patients with BMS-ISR were SirolimusEluting Stents versus Vascular Brachytherapy for In-Stent Restenosis With in Bare-Metal Stents (SISR) and Paclitaxel-Eluting Stents versus Vascular Brachytherapy for In-Stent Restenosis Within Bare-Metal Stents (TAXUS V ISR). Both showed that DES were superior in decreasing restenosis rates and the need for revascularization as compared to brachytherapy at long-term followup ${ }^{17,18}$. The ISAR-DESIRE and RIBS II trials compared BMS-ISR treatment with DES implantation versus POBA and both showed better outcomes with DES. In the recently published RIBS V trial, second generation DES for ISR treatment have shown better outcomes ${ }^{19}$. The introduction of DES has drastically reduced the occurrence of severe neointimal proliferation, the dominant cause of ISR. Newer DES are considered safer than the first generation DES20. European Society of Cardiology recommends DES for the treatment of BMS or DES ISR (COR 1, LOE A). In the SISR trial, the use of Sirolimus Eluting Stents (SES) led to a significantly better angiographic outcomes and a trend to lower occurrence of repeated binary restenosis ${ }^{20}$. Drug Coated Balloons (DCB) has gained a role similar to DES (class I, level of evidence A) The main advantage of DCB in the treatment of ISR is that no new stent scaffold is 
needed within the previously implanted stent. ISAR-DESIRE 3 (2015) and RIBS V (2014) trials have shown same efficacy and long term results with DCB as compared to DES for the treatment of DES ISR. Alfonso et al, in a prospective, multicenter, randomized trial (restenosis intra-stent of bare metal stents: paclitaxel-eluting balloon vs. everolimus-eluting stent: RIBS V) compared DCB with EES in 189 patients with BMS-ISR. The occurrence of the combined clinical outcome measure (cardiac death, myocardial infarction, and TVR) was similar in both groups ${ }^{19}$.

Eighty six percent $(n=43)$ of ISR cases in our study group was treated with DES followed by DEB in $32 \%$ and POBA in $22 \%$. The Intracoronary Stenting or Angioplasty for Restenosis Reduction-Drug-Eluting Stents for In-Stent Restenosis (ISAR-DESIRE) trial was the first randomized study assessing the value of DES in patients with BMS-ISR. The rate of recurrent restenosis was significantly lower with sirolimus $(14.3 \%)$ and paclitaxel-DES $(21.7 \%)$ compared with POBA alone $(44.6 \%)^{21}$. In the Restenosis Intrastent Balloon Angioplasty Versus Elective Sirolimus-Eluting Stenting (RIBS II) trial, which compared sirolimus-DES versus POBA in patients with BMSISR, patients with sirolimus-DES had a significantly lower restenosis rate $(11 \%)$ and superior long-term clinical outcomes ${ }^{22}$. Unfortunately, the treatment of DES-ISR is more challenging, and overall, the outcomes in patients requiring treatment for DES-ISR are worse compared with patients with BMS-ISR. In Intracoronary Stenting and Angiographic Results: Drug Eluting Stents for In-Stent Restenosis 2 (ISAR-DESIRE 2) trial of sirolimus-DES-ISR, the hetero-DES strategy using a paclitaxel-DES failed to reduce restenosis or target vessel revascularization rates compared to repeat stenting with sirolimus-DES23. The Restenosis Intra-Stent: Balloon Angioplasty vs DrugEluting Stent (RIBS III) trial suggested that the use of second-generation DES was superior to first-generation DES, and intravascular imaging for treatment guidance had improved angiographic and clinical outcomes ${ }^{24}$. Despite these benefits of repeat stenting with DES in the mana- gement of DES-ISR, current data suggests that $10-20 \%$ of these patients will go on to develop recurrent ISR ${ }^{21}$.

\section{CONCLUSION}

Diabetes Mellitus was the major patient related risk factor for the development of ISR in our study group. Longer and under expanded stents with geographical miss of the underlying diseases vessel were commonest procedural risk factors. Placement of DES was the commonest treatment modality for ISR in our study group.

\section{CONFLICT OF INTEREST}

This study has no conflict of interest to be declared by any author.

\section{REFERENCES}

1. Omeh DJ, Shlofmitz E. Restenosis [Internet]. StatPearls. 2019 [cited 2019 Oct 23]. Available from: [Internet] http:// www.ncbi.nlm.nih. gov/pubmed/31424723.

2. Her AY, Shin ES. Current management of in-stent restenosis. Korean Circulation J 2018; 48(5): 337-49.

3. Buccheri D, Piraino D, Andolina G, Cortese B. Understanding and managing in-stent restenosis: A review of clinical data, from pathogenesis to treatment. J Thoracic Disease 2016; 8(10): E115062.

4. Nakazawa G, Otsuka F, Nakano M, Vorpahl M, Yazdani SK, Ladich $\mathrm{E}$, et al. The pathology of neoatherosclerosis in human coronary implants: Bare-metal and drug-eluting stents. J Am Coll Cardiol 2011; 57(11): 1314-22.

5. Bainey KR, Norris CM, Graham MM, Ghali WA, Knudtson ML, Welsh RC. Clinical in-stent restenosis with bare metal stents: Is it truly a benign phenomenon?. Int J Cardiol 2008; 128(3): 378-82.

6. Kim MS, Dean LS. In-Stent Restenosis. Cardiovasc Therapeut 2011; 29(1): 190-98.

7. Scott NA. Restenosis following implantation of bare metal coronary stents: Pathophysiology and pathways involved in the vascular response to injury. Advanc Drug Deli Rev 2006; 58(3): 358-76.

8. Konishi Y, Ashikaga T, Sasaoka T, Kurihara K, Yoshikawa S, Isobe M. Comparison of outcomes after everolimus-eluting stent implantation in diabetic versus non-diabetic patients in the Tokyo-MD PCI study. J Cardiol 2016; 67(3): 241-47.

9. Kastrati A, Schömig A, Elezi S, Schühlen H, Dirschinger J, Hadamitzky M, et al. Predictive factors of restenosis after coronary stent placement. J Am Coll Cardiol 1997; 30(6): 1428-36.

10. Elezi S, Kastrati A, Pache J, Wehinger A, Hadamitzky M, Dirschinger J, et al. Diabetes mellitus and the clinical and angiographic outcome after coronary stent placement. J Am Coll Cardiol 1998; 32(7): 1866-73.

11. Choi IJ, Koh YS, Lim S, Kim JJ, Chang M, Kang M, et al. Impact of the stent length on long-term clinical outcomes following newer-generation drug-eluting stent implantation. Am J Cardiol 2014; 113(3): 457-64.

12. Stone GW, Parise H, Witzenbichler B, Kirtane A, Guagliumi G, Peruga JZ, et al. Selection criteria for drug-eluting versus baremetal stents and the impact of routine angiographic follow-up: 2-Year insights from the horizons-ami (harmonizing outcomes 
with revascularization and stents in acute myocardial infarction) trial. J Am Coll Cardiol 2010; 56(19): 1597-04.

13. Garcia-Garcia HM, Shen Z, Piazza N. Study of restenosis in drug eluting stents: New insights from greyscale intravascular ultrasound and virtual histology. EuroIntervention 2009; 5(Suppl D): 84-92.

14. Alfonso F, Zueco J, Cequier A, Mantilla R, Bethencourt A, López-Minguez JR, et al. A randomized comparison of repeat stenting with balloon angioplasty in patients with in-stent restenosis. J Am Coll Cardiol 2003; 42(5): 796-05.

15. Albiero R, Silber S, Di Mario C, Cernigliaro C, Battaglia S, Reimers B, et al. Cutting balloon versus conventional balloon angioplasty for the treatment of in-stent restenosis: Results of the restenosis cutting balloon evaluation trial (RESCUT). J Am Coll Cardiol 2004; 43(6): 943-49.

16. Leon MB, Teirstein PS, Moses JW, Tripuraneni P, Lansky AJ, Jani $\mathrm{S}$, et al. Localized intracoronary gamma-radiation therapy to inhibit the recurrence of restenosis after stenting. N Engl J Med 2001; 344(4): 250-56.

17. Holmes DR, Teirstein P, Satler L, Sketch M, O'Malley J, Popma JJ, et al. Sirolimus-eluting stents vs vascular brachytherapy for in-stent restenosis within bare-metal stents: The SISR randomized trial. J Am Med Assoc 2006; 295(11): 1264-73.

18. Stone GW, Ellis SG, O'Shaughnessy CD, Martin SL, Satler L, Mc Garry T, et al. Paclitaxel-eluting stents vs vascular brachy-therapy for in-stent restenosis within bare-metal stents: The TAXUS V ISR randomized trial. J Am Med Assoc 2006; 295(11): 1253-63.

19. Alfonso F, Pérez-Vizcayno MJ, Cárdenas A, García Del Blanco B, Seidelberger B, Iñiguez $\mathrm{A}$, et al. A randomized comparison of drug-eluting balloon versus everolimus-eluting stent in patients with bare-metal stent-in-stent restenosis: The RIBS v clinical trial (restenosis intra-stent of bare metal stents: Paclitaxel-eluting balloon vs. everolimus-eluting stent). J Am Coll Cardiol 2014; 63(14): 1378-86.

20. Park KW, Kang SH, Velders MA, Shin DH, Hahn S, Lim WH, et al. Safety and efficacy of everolimus-versus sirolimus-eluting stents: A systematic review and meta-analysis of 11 randomized trials. Am Heart J 2013; 165(2): 241-50.

21. Kastrati A, Mehilli J, Von Beckerath N, Dibra A, Hausleiter J, Pache J, et al. Sirolimus-eluting stent or paclitaxel-eluting stent vs balloon angioplasty for prevention of recurrences in patients with coronary in-stent restenosis: A randomized controlled trial. J Am Med Assoc 2005; 293(2): 165-71.

22. Alfonso F, Pérez-Vizcayno MJ, Hernandez R, Bethencourt A, Martí V, López-Mínguez JR, et al. A Randomized Comparison of Sirolimus-Eluting Stent With Balloon Angioplasty in Patients With In-Stent Restenosis. Results of the Restenosis Intrastent: Balloon Angioplasty Versus Elective Sirolimus-Eluting Stenting (RIBS-II) Trial. J Am Coll Cardiol 2006; 47(11): 2152-60.

23. Byrne RA, Cassese S, Windisch T, King LA, Joner M, Tada T, et al. Differential relative efficacy between drug-eluting stents in patients with bare metal and drug-eluting stent restenosis; Evidence in support of drug resistance: Insights from the ISARDESIRE and ISAR-DESIRE 2 trials. Euro Intervent 2013; 9(7): 797-02.

24. Alfonso F, Pérez-Vizcayno MJ, Dutary J, Zueco J, Cequier A, García-Touchard A, et al. Implantation of a drug-eluting stent with a different drug (switch strategy) in patients with drugeluting stent restenosis: Results from a prospective multicenter study (RIBS III [restenosis intra-stent: Balloon angioplasty versus drug-eluting stent]). JACC Cardiovasc Interv 2012; 5(7): 728-37. 